\title{
틀 RPI
}

\section{Gestão Pública e o Desempenho: o Estudo de Caso sobre a Gestão por Resultados do Governo do Estado do Ceará}

Public Management and Performance: a Case Study on the Results Management of the Government of the State of Ceará

\author{
Samuel Leite Castelo ${ }^{1}$
}

DOI: $10.22478 / u f p b .2525-5584.2020 v 5 n 1.51204$

Recebido em: $17 / 03 / 2020$

Aprovado em: 08/04/2020

\begin{abstract}
Resumo: Estudo sobre o desempenho no setor público sob o enfoque da Gestão pública brasileira e cearense. om vistas a conformar o método investigativo, recorreu-se a uma pesquisa qualitativa, de caráter exploratório, por meio de uma abordagem metodológica mediante a análise documental e via estudo de caso. O escrito mostra o percurso da Gestão pública e o desempenho no Brasil, identificando os principais fatos que caracterizaram estes fenômenos e como se comportou a cultura por resultados e seus reflexos no desempenho do governo do Ceará. Os achados de estudos anteriores sobre gestão e medição do desempenho no setor público não foram suficientemente esclarecidos. A pesquisa ora relatada procura preencher esta lacuna, examinando a influência da gestão de resultados no desempenho do setor público. Os resultados evidenciados denotam que as novas práticas introduzidas pela gestão de resultado demonstraram sensíveis avanços na política econômica, fiscal e administrativa do Estado, porém os progressos ocorridos sob os aspectos ambiental e social não foram suficientes para atenuar as desigualdades sociais e territoriais. A cultura da gestão por resultado, também, mostra este ensaio diferente em relação a demandas precedentes.
\end{abstract}

Palavras-chave: Desempenho; Gestão Pública; Gestão por Meio de Resultados; Serviço Público.

Abstract: Study on performance in the public sector under the focus of Brazilian and Ceará Public Management. aimed at conforming the investigative method, a qualitative research of exploratory character was used, through a methodological approach through documentary analysis and through case study. The writing shows the path of public management and performance in Brazil, identifying the main facts that characterized

\footnotetext{
${ }^{1}$ Universidade Estadual do Ceará. E-mail: samuel.castelo@uece.br.
} 
these phenomena and how the culture was behaved for results and their reflections on the performance of the government of Ceará. The findings of previous studies on management and measurement of performance in the public sector were not sufficiently clarified. The research reported here seeks to fill this gap, examining the influence of results management on the performance of the public sector. The results show that the new practices introduced by the result management demonstrated significant advances in the economic, fiscal and administrative policy of the State, but the progress made under the environmental and social aspects was not enough to mitigate social and territorial inequalities. The culture of result management, too, shows this essay different from previous demands.

Keywords: Performance; Public Management; Management by Results; Public Service.

\section{Introdução}

A perspectiva moderna sobre a Gestão Pública revela não só uma recorrência de temas, dilemas e paradoxos, mas também uma constante busca de mais conhecimentos para a solução de implicações práticas, tais como gerenciar e medir o desempenho (Mota, 2013; Capobiango, Nascimento, Silva, Faroni, 2013).

Na prática, existem pressões para mais e melhores serviços, de solução imediata aos problemas econômicos, fiscais e sociais, pelo uso eficiente de recursos, de prestação de contas e da transparência dos atos dos governantes (Mota, 2013; Bao et al., 2013; Cavalcante, 2019).

Bouckaert \& Halligan, (2008) apontam que a cultura administrativa é um fator decisivo que influencia a implantação dos processos da gestão e medição de desempenho. De igual maneira, a atitude de políticos e gerentes é relevante no design e na implementação das reformas, dos processos administrativos e gerenciais (Pollitt \& Bouckaert, 2004; Brusca, Manes Rossi e Aversano, 2017).

Com base na literatura sobre desempenho governamental, objetiva-se, neste passo, proceder a um estudo sobre o desempenho no contexto da Gestão Pública brasileira e da gestão por resultados no Governo do Ceará. No âmbito desse escopo, busca-se alcançar estes objetivos específicos: a) evidenciar a evolução das abordagens da Gestão Pública e o desempenho; b) descrever as fases da Gestão Pública brasileira; c) exibir o modelo da gestão por resultado do Governo do Ceará.

A metodologia utilizada consistiu numa revisão bibliográfica e documental da literatura e dispositivos infraconstitucionais aplicados ao desempenho governamental e sobre a Gestão Pública brasileira e a respeito da gestão por resultado aplicada do Ceará.

Revista Brasileira de Políticas Públicas e Internacionais, v. 5, n. 1, abr./2020, pp. 105-128. 
Com efeito, o estudo é classificado como descritivo e exploratório, com análise qualitativa, por meio de análise documental e estudo de caso.

Os principais achados deste ensaio reconhecem o papel importante das práticas da gestão de resultado do Estado na melhoria da performance fiscal, econômica e administrativa. Para este papel, contribuem para as mudanças culturais, normativas e em seus processos organizacionais. Os resultados também evidenciam os avanços nos quesitos sociais e ambientais, porém estão, ainda, bem distantes de impor um termo à pobreza, à miséria e às desigualdades sociais e territoriais.

Os dados deste estudo permitem a visualização da cultura de resultados, como os processos melhoraram as influências das políticas públicas e acrescentam valor público. Também há de se entender que é necessário um sistema de medição de performance cujo diagnóstico eficiente dos programas de governo deve ser complementar a uma interação eficaz com as capacidades organizacionais.

Este escrito está organizado em cinco secções, inclusa a introdução ora relatada. Na próxima, encontram-se a revisão de literatura. Na secção imediatamente posterior, é mostrado o contexto do estudo, para, sequentemente, se delinear a análise de estudo de caso, e as considerações finais. No segmento de remate, evidenciam-se os principais resultados e se oferecem propostas para investigação futura.

\section{Enquadramento Teórico}

\subsection{A Evolução das Escolas da Gestão Pública e do Desempenho}

A evolução da Gestão Pública perfaz cinco "eras da administração" (Bao et al., 2013). A primeira chama-se de pré-clássica porque precede a criação consciente da Administração Pública como uma seara formal de estudo. Neste período, evidencia-se a importância dos gestores públicos no processo com os políticos em estabelecer a confiança e a legitimidade da ordem política e jurídica, bem como do desempenho do governo (Bao et al., 2013; Mota, 2013).

O desempenho, nesse tempo, relacionava-se com a medição: o que, por que e como as atividades deveriam ser mensuradas e reportadas, na intenção da melhoria do resultado governamental (Eliuz et al., 2017; Monteduro, 2017). Também o desempenho foi vinculado a sua avaliação, sendo percebido como orientador da direção de prioridades

Revista Brasileira de Políticas Públicas e Internacionais, v. 5, n. 1, abr./2020, pp. 105-128. 
e foi utilizado para avaliar o mérito e a qualidade do esforço individual e coletivo (Ensslin et al., 2017).

A segunda "era" refere-se à gestão burocrática. Para Bao et al. (2013), a gestão clássica preocupa-se com a eficiência administrativa, pela competência de suas atividades e regulação dos seus atos e decisões. O foco baseava-se na definição de metas e objetivos por meio de um sistema hierárquico.

Nesta fase, houve uma transformação com base em regras e processos para o mercado. Em decorrência das reformas gerenciais, ocorreu outro impulso, então direcionado para Gestão e Medição de Desempenho (GMD) (Monteduro, 2017).

Nessa época, os Estados Unidos buscavam inspiração nos modelos europeus para práticas democráticas. Presumiam-se as constituições e as leis como fundamentos lógicos e necessários para garantir a democracia. Problemas administrativos e ineficiência na prestação dos serviços revelavam, todavia, a insuficiência da ordem jurídica. Constatou-se que a criação de instituições políticas sólidas e também responsáveis não seria capaz, por si, de operar para que se obtivesse um desempenho efetivo (Freitas, 1999; Mota, 2013).

No Estado moderno, ao assumir dimensões de prestação de serviços, a eficiência passou a ser um estádio importante. Surgiam propostas para uma administração independente da política e fundamentada em estudos e conhecimentos próprios, como uma ciência (Mota, 2013).

Posteriormente, houve uma busca de princípios de Administração. O avanço foi, no entanto, concomitante às frustrações e decepções com a ineficiência da Administração Pública. Tentativas de implantar neutralidade política e profissionalização da gestão pública enfrentavam obstáculos políticos (Mota, 2013).

O estudo da Gestão Pública deveria considerar o contexto, por conseguinte, uma visão mais abrangente e holística. O modelo era caracterizado pelo foco excessivo de controle, tendo como resultado a redução da eficiência, de mecanismos de transparência e de objetividade - daí a morosidade e o privilégio de interesses de grupos específicos e o baixo desempenho (Mota, 2013).

Admitindo-se como impossíveis a neutralidade e o distanciamento da política, bem assim a universalidade de princípios práticos, a melhor proposta seria comprometer os gestores públicos com valores essenciais - conformados em ética, equidade, eficiência e eficácia - que condicionariam os comportamentos e as práticas gestoras.

Revista Brasileira de Políticas Públicas e Internacionais, v. 5, n. 1, abr./2020, pp. 105-128. 
O discurso hegemônico em curso configurou o governo como havendo se tornado insustentável e financeiramente sobrecarregado. A capacidade de resposta das autoridades e das prioridades do governo se fez alvo de debates. Portanto, com uma intensa componente política, ideológica e econômica, experimentou curso um amplo movimento de reformas administrativas destinadas a mudar o papel e funcionamento do Estado. Assistidas por intensivo patrocínio de organizações multilaterais, as reformas em busca de melhores desempenhos ocorreram nos países centrais (Freitas, 1999; Cavalcante, 2019).

Aflorou, assim, o movimento da Nova Gestão Pública (NGP), a "terceira era", firmada por um amplo conjunto de crenças, doutrinas e experiências que serviram como um quadro de referência na avaliação e redesenho do setor público. Sob a agenda da NGP, a GMD apareceu como uma maneira de reinventar e melhorar a eficiência, eficácia e qualidade do governo (Gomes, Mendes, Carvalho, 2017).

A NGP emergiu intensivamente baseada em uma narrativa sobre as deficiências do modelo burocrático e sugeriu reformas com amparo em doutrinas neoliberais, destinadas à reconfiguração do papel do Estado (Mota, 2013; Cavalcante, 2019).

A NGP consistia num conjunto de alterações deliberadas de estruturas e processos, com o objetivo de obter melhor desempenho. É um modelo prescritivo, pósburocrático para estruturação da gestão, com suporte nos princípios e diretrizes da competitividade e de organizações privadas (Mota, 2013; Verbeeten and Speklé, 2015; Cavalcante, 2019).

Ex positis, a gestão deveria apenas direcionar os serviços, e não os executar. Havia uma preferência por terceirizar e contratar fora. Por meio de vários provedores privados, poderiam ser usados os benefícios da competição entre eles, evitando monopólios e permitindo maior flexibilidade (Mota, 2013).

O foco no desempenho levaria os governos a aumentar a produtividade, a relação custo-benefício na prestação de serviços (Carter, Bob, 2013). Além disso, a introdução de mecanismos de concorrência entre agências governamentais, os instrumentos de flexibilidade gerencial, eram antevistos como incentivos e meios para melhoria da gestão (Cavalcante, 2019).

Bouckaert e Halligan,(2008) assinalam que a NGP consiste em um fenômeno de dois níveis. No de feição política, a doutrina propaga a melhoria dos serviços públicos por meio da importação de conceitos, técnicas e princípios da iniciativa privada. 
Entrementes, no nível de cariz mais técnico, o conjunto de conceitos e práticas específicas inclui ênfase no desempenho, medindo os custos, processos e indicadores de resultados; preferência por formatos organizacionais mais enxutos e especializados, com mecanismos típicos do mercado, tais como: abertura à competição, pagamento por desempenho e foco no serviços ao cliente-cidadão.

O governo concentraria seus esforços nas suas atividades essenciais e exclusivas, direcionando e garantindo o suprimento das necessidades da sociedade por meio de transferências para o setor privado e para o terceiro setor (Mota, 2013; Cavalcante, 2019).

A crença em mudanças favorecia a proposta de reinvenção da Gestão Pública, pois elas trouxeram novo otimismo. Era, portanto, um novo paradigma de transformar o setor público por meio de reformas administrativas que enfocam resultados em termos de eficiência, eficácia e qualidade na teoria da governança. Assim, a NGP transitou para a governança (Jurnali, 2015; Han, Kim, 2017).

A Governança Pública (GP), a quarta escola, abrange participação, estado de direito, transparências, capacidade de resposta, consenso de orientação, equidade, eficiência e eficácia, responsabilidade, visão estratégica e equidade. Como tal, a disponibilidade e a disseminação de informações sobre políticas, programas e resultados relativos a serviços são os elementos centrais, cujo principal objetivo radica em melhorar a prestação de contas, porque oferece maior atenção aos mercados, à GMD, à satisfação dos cidadãos e à transparência do governo (Jurnali, 2015).

A GP constitui um formato de burocracia, de coordenação e divisão de trabalho, influenciando no planejamento, na gestão e tomada de decisão. Estas estruturas de governança estabelecem modelos de GMD que busquem uma interconexão das políticas públicas, por intermédio de novos processos de avaliação, e que possibilitem interseções dos setores público e privado (Tabi; Verdon, 2014; Virtanen, Vakkuri, 2015).

Com isso, a GP provocou mudanças e consequências, como: a criação de meios e instrumentos de políticas; interesse em redes além de hierarquias, arranjos de parcerias entre organizações públicas, privadas e sem fins lucrativos; ênfase nas habilidades de negociação e persuasão - e revitalizou as habilidades da GMD. (Bao et al.,2013; Han, Kim, 2017; Cavalcante, 2019).

A modernização pela GP envolve o processo de moldar um novo desenho institucional baseado na definição de metas políticas, de atendimento de interesse dos 
grupos que exercem o poder por meio de um sistema de normas (Barabashev, Klimenko, 2017; Han, Kim, 2017).

De fato, a GP postula a natureza complexa e fragmentada da definição e de processos de implementação de políticas (Dal Molin, Turri, Agasisti, 2017). Estas condições organizacionais e institucionais em cada nível da administração podem influenciar na implementação de reformas (Dal Molin, Turri, Agasisti, 2017).

Segundo Bao et al. (2013), a GP enfatiza três características para estabelecer a confiança e a legitimidade. Primeiramente, é centrada no valor, pois se argumenta que o objetivo é promover o bem público, não apenas melhorar a eficiência, a eficácia ou a capacidade de resposta na implementação de um determinado programa. A segunda característica é enfatizar a criação de processos que facilitem a geração de acordos implementáveis entre stakeholders, que produzirá o máximo valor público. E a característica final é a criação do bem público como um processo de coprodução, envolvendo o cidadão, o mercado privado e os setores sem fins lucrativos (Cavalcante, 2019).

O papel do governo não é regular, distribuir ou redistribuir benefícios públicos, mas também servir como um agente catalisador na propriedade compartilhada do bem público (Bao et al., 2013; Cavalcante, 2019). Em vez de desagregação, a integração; em vez de competição, ênfase na colaboração; e, finalmente, a substituição da motivação pecuniária pela profissionalização da burocracia e da inclusão de agentes sociais na formulação de políticas (Cavalcante, 2019).

As três características discutidas emanam de que o desempenho do governo precisa ser visto sob a perspectiva da integridade orgânica de um sistema político no qual os setores público, privado e sem fins lucrativos trabalham juntos para criar a singularidade de uma determinada comunidade. Essa visão enfatiza a influência sinérgica das instituições sociais na criação de um sistema compartilhado de valores, acordo sobre os processos e estruturas de governança e os respectivos papéis que todos os setores desempenham na criação do bem comum (Bao et al., 2013; Cavalcante, 2019).

O último estádio refere-se ao desempenho baseado em valor. Abordagem centrada no valor combina estratégia e gestão de desempenho. Esta abordagem facilita a integração da liderança estratégica com as preocupações mais táticas e operacionais de GMD (Bao et al., 2013). Destaca a importância das habilidades da gestão de relacionamento no estabelecimento de confiança no governo, que exige dos gestores e 
funcionários situarem no centro os valores da política no projeto. Negocia-se tanto no nível horizontal e vertical, bem como dentro e fora compartilhando desempenho entre vários stakeholders. (Bao et al., 2013).

Esta abordagem expande a capacidade de aprendizado que requer dos participantes a criação imaginativa de soluções. Estimula a autorreflexão sobre o melhor curso de ação e os critérios de desempenho. Os valores são necessários para a criação da integridade moral, independentemente de se lidar com pessoas ou sistemas políticos. $\mathrm{Na}$ ausência dessa integridade compartilhada, os participantes do processo recorrerão ao confronto e ao uso da força para lidar com suas insatisfações (Bao et al., 2013).

Finalmente, esta matéria oferece rica oportunidade para preparar uma agenda de pesquisa, concentrando-se no modo como as diferenças nos valores moldam o significado da eficiência, da eficácia e dos resultados do governo.

\subsection{As Reformas da Gestão Pública Brasileira Direcionadas para o Desempenho}

A Gestão Pública brasileira, primeiramente, constituiu-se num Estado Patrimonialista que ficou caracterizado por um intenso interesse público e o privado, onde o Ente estatal era a Família Real.

A reforma administrativa de 1936 focou as atividades de administração geral; buscou montar um corpo de burocratas; baseou-se nos "princípios de administração" e no modelo prescrito na teoria taylorista/fayoliana/weberiana (Capobiango, Silva, Faroni, 2013; Faria, Faria, 2017).

Surgiu depois o modelo burocrático, que procurou combater os excessos do estalão anterior. $\mathrm{O}$ modelo burocrático era baseado nas modalidades de autoridade racional-legal, explicitando a impessoalidade nas relações, a formalização das comunicações, a divisão do trabalho, a hierarquização de autoridade e o mérito baseado na competência (Bresser-pereira, 1999).

Nesse âmbito, implementou-se pelo Decreto-Lei no 200/67 a descentralização dos quadros da Administração Federal; da Gestão Pública para a particular; da União para os municípios; e o estabelecimento dos sistemas administrativos (Capobiango, Silva, Faroni, 2013; Faria, Faria, 2017).

Esta norma materializou a descentralização por meio de criação e ampliação de autarquias, fundações e empresas estatais, dando maior autonomia do que aos órgãos da Administração Direta. Apesar desse avanço, ocorreu a "Contra-Reforma" introduzida 
pela Constituição federal (Bresser-pereira, 1999). Malgrado o exposto, mostraram-se avanços na exigência de concurso público e da transferência de ações sociais da esfera federal para as outras esferas federativas.

Essa periodização político-institucional não separou as reformas administrativas dos movimentos estruturais ocorridos no plano político e econômico à extensão do processo de modernização do País, incluindo transformações ocorridas no plano gerencial (Capobiango, Silva, Faroni, 2013; Faria; Faria, 2017).

O mercado impõe a agilidade e uma intensa capacidade de adaptação a mudanças, em virtude da complexidade tecnológica. Portanto, o modelo burocrático, com suas disfunções, não atendeu aos objetivos institucionais, sendo substituído pelo padrão gerencial.

A Reforma Gerencial possui três dimensões interligadas - social, econômica e administrativa. A primeira dirigia-se ao bem-estar da população; já a dimensão econômica visava a uma forte intervenção estatal; e a vertente administrativa estava ligada a crise de governabilidade e credibilidade do Estado (Paes de Paula, 2005).

Logo, foi resposta à crise na qual o Estado passava, como também, estratégia de redução de custos para tornar mais eficiente a máquina administrativa (Paes de Paula, 2005; Mota, 2013; Cavalcante, 2019).

O Modelo Gerencial teve destaque com a implantação do Ministério da Administração Federal e Reforma do Estado, que passou a ter como função a operacionalização e a elaboração do Plano Diretor da Reforma do Aparelho do Estado.

A Reforma Gerencial promoveu a descentralização dos serviços sociais para estados e municípios; delimitou a área de atuação do Estado, estabelecendo uma distinção entre as atividades exclusivas do Estado e atividades sociais e científicas, que foram transferidas para o setor público não estatal, e a produção de bens e serviços para o mercado; a distinção entre as atividades do núcleo estratégico, que devem ser efetuadas por políticos e altos funcionários, e as atividades de serviços, que podem ser objeto de contratações externas; a separação entre a formulação de políticas e sua execução; maior autonomia para agências executivas; assegurar a responsabilização por meio da administração por objetivos, da criação de controle social, em combinação com o aumento da transparência, reduzindo-se, concomitantemente, o papel do controle interno (Bresser-pereira, 1999; Faria, Faria, 2017).

Revista Brasileira de Políticas Públicas e Internacionais, v. 5, n. 1, abr./2020, pp. 105-128. 
O modelo de reforma tinha três pilares: (1) propunha uma nova classificação do que seja propriedade pública; (2) distinguia no seu texto os três tipos de administração pública; e (3) segmentava três níveis necessários de atuação do Estado.

Primeiro, a propriedade pública ficaria classificada em dois tipos: a propriedade pública estatal e a propriedade pública não estatal. A primeira são os bens sob o controle estatal e a segunda são todos os bens de interesse público, mesmo que esses não sejam do Estado.

O segundo pilar detalha os três tipos de administração pública: a patrimonialista, a burocrática e a gerencial. Ressalta-se que a Administração Gerencial não nega todos os princípios da Administração Burocrática, que se baseia nos resultados e não nos processos (Faria ,Faria, 2017).

O terceiro delimitou os níveis de atuação do Estado em três setores de atividades: atividades exclusivas; os serviços sociais e científicos não-exclusivos; e a produção de bens e serviços para o mercado (Bresser-pereira, 1999).

As atividades exclusivas do Estado são indelegáveis, como, forças armadas, segurança, arrecadação e fiscalização tributária etc. Os serviços não exclusivos são aqueles cujos bens e serviços públicos podem ser fornecidos por organizações públicas não estatais ou por entidades privadas sujeitas ao controle social. E a produção de bens e serviços para o mercado encontra-se nas atividades econômicas próxima à estrutura do Estado.

O núcleo estratégico tem a função de formular, supervisionar e avaliar a implementação de políticas públicas, sendo composto pela cúpula dos Três Poderes e Ministério Público.

Após o governo de FHC, surgiu a vertente social. Manifesta-se nas experiências alternativas da Gestão Pública e possui raízes no ideário dos herdeiros políticos pela redemocratização do País, com destaque para os movimentos sociais e as organizações não governamentais (Paes de Paula, 2005).

Nos governos seguintes, no entanto, observou-se a continuidade das práticas gerencialistas, inclusive no que se refere às políticas sociais que se consolidavam no campo "movimentalista" (Paes de Paula, 2005).

O campo "movimentalista" centrava-se na reivindicação da cidadania e no fortalecimento do papel da sociedade civil na condução da vida política, pois questionava o Estado como protagonista da gestão, e da ideia de público como sinônimo de estatal.

Revista Brasileira de Políticas Públicas e Internacionais, v. 5, n. 1, abr./2020, pp. 105-128. 
Nesse contexto, multiplicaram-se pelo País governos com propostas inovadoras, que abrigavam variadas experiências de participação social. Ampliava-se, pois, assim a inserção do campo "movimentalista", que passou a atuar nos governos municipais e estaduais (Jacobi, 2000).

\section{Estudo de Caso}

\subsection{A Gestão por Resultados do Governo do Ceará}

A Gestão por Resultados (GpR) pode ser conceituada como processos organizacionais que centram a atenção nos aspectos comportamentais e em meios gerenciais para implantação da orientação estratégica governamental (CEARÁ, 2019b).

A GpR busca fazer uma cultura, com o foco em alcançar os resultados estratégicos; promover uma visibilidade global a respeito das prioridades da estratégia por meio das entidades; sistematizar maior agilidade e melhor informação; garantir os recursos e o foco organizacional e financeiro necessário para os principais objetivos do Estado; e estimular a aprendizagem por meio do acompanhamento e monitoramento (CEARÁ, 2019a).

Segundo MARCOPLAN (2016) e CEARÁ, (2019a), os princípios da GpR são: Foco em públicos-alvo claros e inequívocos; Orientação para resultados de longo prazo; Flexibilidade e agilidade administrativa; Valorização e comprometimento profissional com resultados; Governança pública integrada, convergente e colaborativa; Participação e controle social; e Sustentabilidade fiscal e financeira.

O Estado, em 2003, adotou o modelo GpR e a sua adoção se deu em um contexto de forte restrição fiscal (Maciel, Correa, et al., 2019). Neste contexto, foi implementado o Comitê Gestão para Resultados e Gestão Fiscal (COGERF), visando a assessorar o Governador na definição das diretrizes e medidas a serem seguidas pelos órgãos. Também foi criada a matriz de resultados estratégicos e instituída a Sala de Situação para acompanhamento dos indicadores do Governo, meios que traduziram o esforço deste para a institucionalização da GpR (Maciel, Correa et al., 2019; Maciel, Duarte et al., 2019).

A GpR teve uma concepção empreendedora, buscando altos padrões de eficiência, eficácia e efetividade, com ética e transparência, com o objetivo de reduzir custos e com foco na satisfação dos cidadãos (Maciel, Correa et al., 2019; Maciel, Duarte et al., 2019).

Revista Brasileira de Políticas Públicas e Internacionais, v. 5, n. 1, abr./2020, pp. 105-128. 
Conforme Holanda (2006) e Maciel, Duarte et al. (2019), a GpR priorizou três vertentes de atuação: propor medidas para obtenção do equilíbrio fiscal; promover um choque da gestão e modernizar a estrutura administrativa; e obter operações de crédito para financiar as atividades estatais. Outro avanço foi a elaboração dos planos estratégicos das secretarias e orientação no entendimento do Plano de Governo e, por conseguinte, o alinhamento dos planos setoriais com as intenções de Governo. Com esse esforço, todas as secretarias passaram a contar com uma matriz de resultados e a vinculação do resultado de governo; redução do número de programas; sistema informatizado com foco nas contas públicas, ações governamentais, indicadores socioeconômicos e no perfil municipal (MARCOPLAN, 2016).

Em 2006, a crescente orientação para resultados destacou-se com a incorporação de um capítulo de análise nos relatórios de prestação de contas anuais do Tribunal de Contas do Estado (Holanda, 2006; Maciel, Duarte, et al., 2019; MARCOPLAN, 2016). Houve, ainda, a definição da carteira de projetos prioritários, o painel de controle dos resultados e, por fim, o Sistema de Monitoramento de Ações e Projetos Prioritários, instrumentos que contribuíam para o monitoramento da execução física e financeira dos projetos (Maciel, Correa et al., 2019). Este sistema visava a um melhor gerenciamento da carteira de projetos (Maciel, Correa et al., 2019; Maciel, Duarte et al., 2019).

Em 2007, a elaboração do Modelo de Gestão foi definida na Lei n ${ }^{\circ} 13.875 / 2007$, que contemplava a implementação da estrutura de monitoramento de projetos, os quais passaram a ter níveis diferenciados de monitoramento conforme sua classificação em: estratégicos de governo, estratégicos setoriais e complementares (MARCOPLAN, 2016; Maciel, Correa et al, 2019).

Em 2009, instituiu-se a Rede Estadual de Planejamento, com o objetivo de conduzir os processos de planejamento, orçamento e gestão de projetos. A estrutura da rede passou a contar com a Unidade Setorial de Planejamento, cuja finalidade era unificar a coordenação dos instrumentos de planejamento, com os escritórios de monitoramento de projetos, com o objetivo de realizar o monitoramento intensivo dos projetos prioritários (MARCOPLAN, 2016).

Outro avanço importante veio com a metodologia participativa de elaboração do Plano Plurianual (PPA) 2016-2019. Nesse ínterim, a feitura do PPA contou com a participação e o apoio da sociedade civil.

Revista Brasileira de Políticas Públicas e Internacionais, v. 5, n. 1, abr./2020, pp. 105-128. 
Em 2016, o Governo verificou a necessidade da retomada da visão estratégica e de fortalecimento da GpR. Neste contexto, encontrou-se um panorama de fragilidades na implementação do modelo da gestão, além da necessidade de investimento e melhoria nos indicadores estratégicos (Maciel, Correa et al., 2019).

Esta realidade trouxe o desafio de criar um sistema abrangente de monitoramento e avaliação, de modo que os resultados e os esforços fossem mensurados, contribuindo para a tomada de decisão baseada em evidências, na priorização dos recursos públicos e na transparência (Maciel, Correa et al, 2019; Piovan et al., 2019).

Daí, o Governo modificou para um sistema abrangente de governança (Piovan et al., 2019). Este novo modelo tem uma estrutura de governança, conectando os processos de planejamento e monitoramento com a pactuação de compromissos anuais, efetivados por meio do Acordo de Resultados, que alinha os esforços à estratégia, articulando uma cadeia lógica entre os insumos para a execução das iniciativas, que, por sua vez, produzem entregas que contribuem para o alcance dos resultados planejados (Maciel, Correa et al, 2019).

Visa, portanto, à consecução no curto prazo das estratégias estabelecidas no Plano Estratégico de Desenvolvimento e nas Agendas Estratégicas Setoriais, obedecendo às diretrizes estabelecidas do PPA vigente. Uma vez definido o acordo, se inicia o monitoramento das ações, que culmina na avaliação do desempenho da Secretaria ao final do período (Maciel, Duarte et al., 2019).

Nesta abordagem, evitam-se as decisões tomadas com base em interesses privados e avança para promover e redirecionar as políticas públicas na realização de mudanças eficazes e eficientes (Maciel et al, 2019).

Figura 01: Evolução do Modelo de GpR do Governo do Ceará

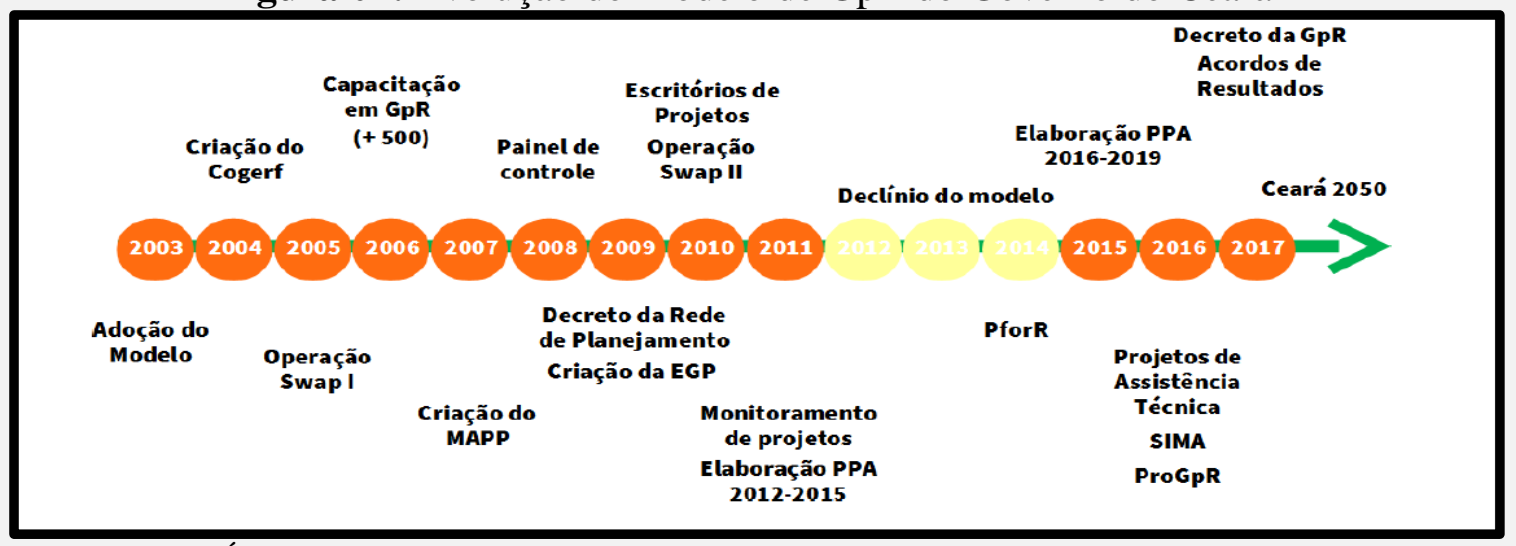

Fonte: (CEARÁ, 2019a).

Revista Brasileira de Políticas Públicas e Internacionais, v. 5, n. 1, abr./2020, pp. 105-128. 


\subsection{Análise do modelo GpR do governo do estado do Ceará}

O Ceará ocupa uma área de 148,8 mil km², equivalente a 1,7\% do Território Nacional, e, em 2019, a população foi estimada em 9,1 milhões de habitantes, representando $16 \%$ da população do Nordeste e $4,3 \%$ do contingente demográfico do Brasil. Em termos de densidade demográfica, obteve um indicador de 56,76 habitantes $/ \mathrm{km}^{2}$. No que se refere à taxa de mortalidade infantil, esta diminui ao longo dos anos, conforme o gráfico 1 (IBGE, 2019).

Em relação aos gastos públicos, em receitas realizadas, em 2017, arrecadou o montante de $\mathrm{R} \$ 28.4$ bilhões de reais e aplicou o valor de $\mathrm{R} \$ 24,6$ bilhões de reais, apresentando um superávit orçamentário de 3,8 bilhões de reais, demonstrando equilíbrio fiscal (IBGE, 2019)

Gráfico 01: Taxa de Mortalidade Infantil

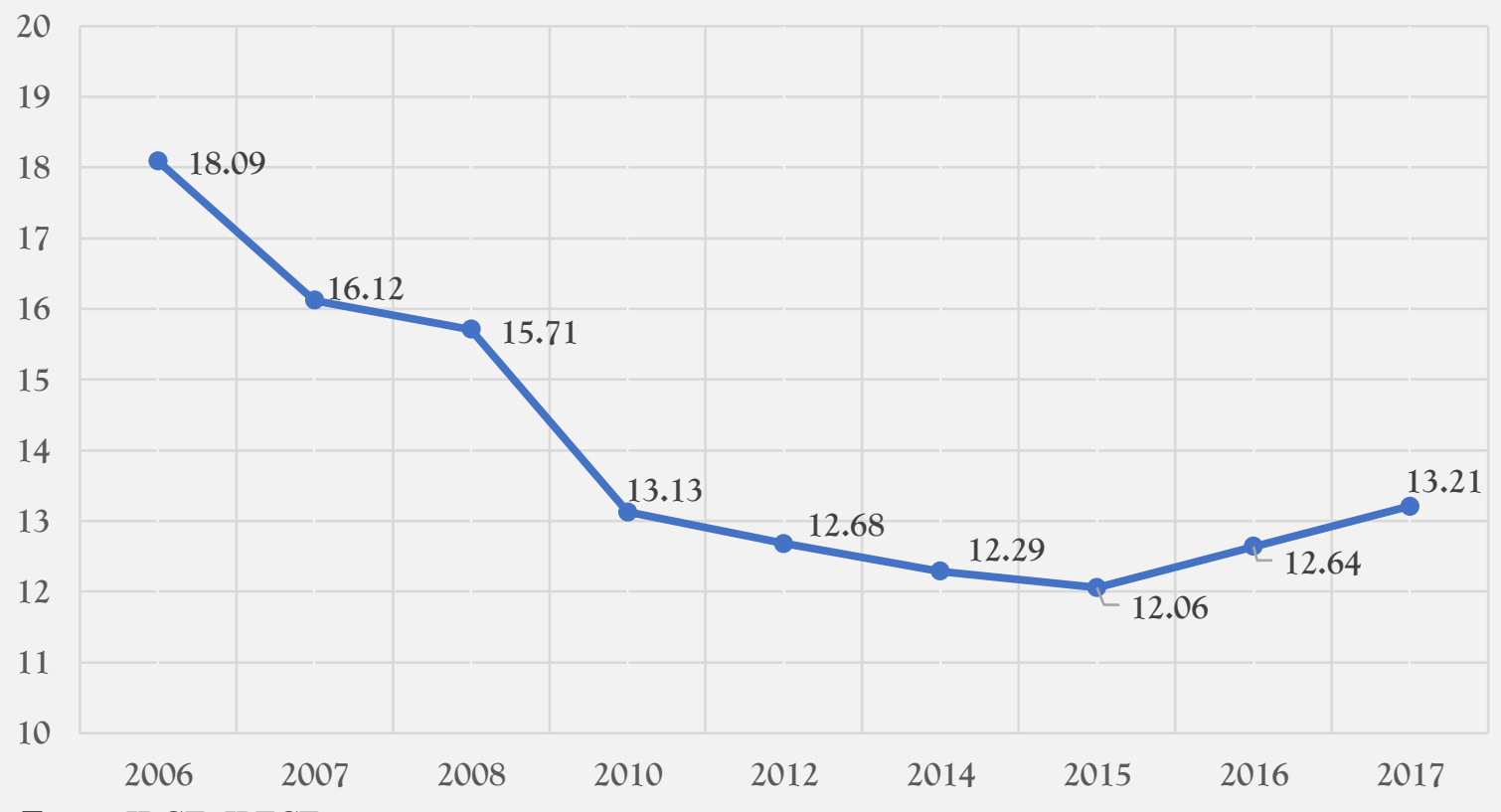

Fonte: IBGE, IPECE.

Neste mesmo período, o Ceará ocupou o $3^{\circ}$ lugar no ranque, foi dos estados que mais investiu em infraestrutura e em equipamentos públicos, aplicando 989 milhões de reais (IBGE, 2019). Corroborando os dados expressos há pouco, em 2018, a Federação das Industria do Rio de Janeiro indicou o Governo do Ceará com a melhor situação fiscal do Brasil.

Gráfico 02: Evolução PIB Trimestral Brasil e Ceará 2006.3/2019.3 


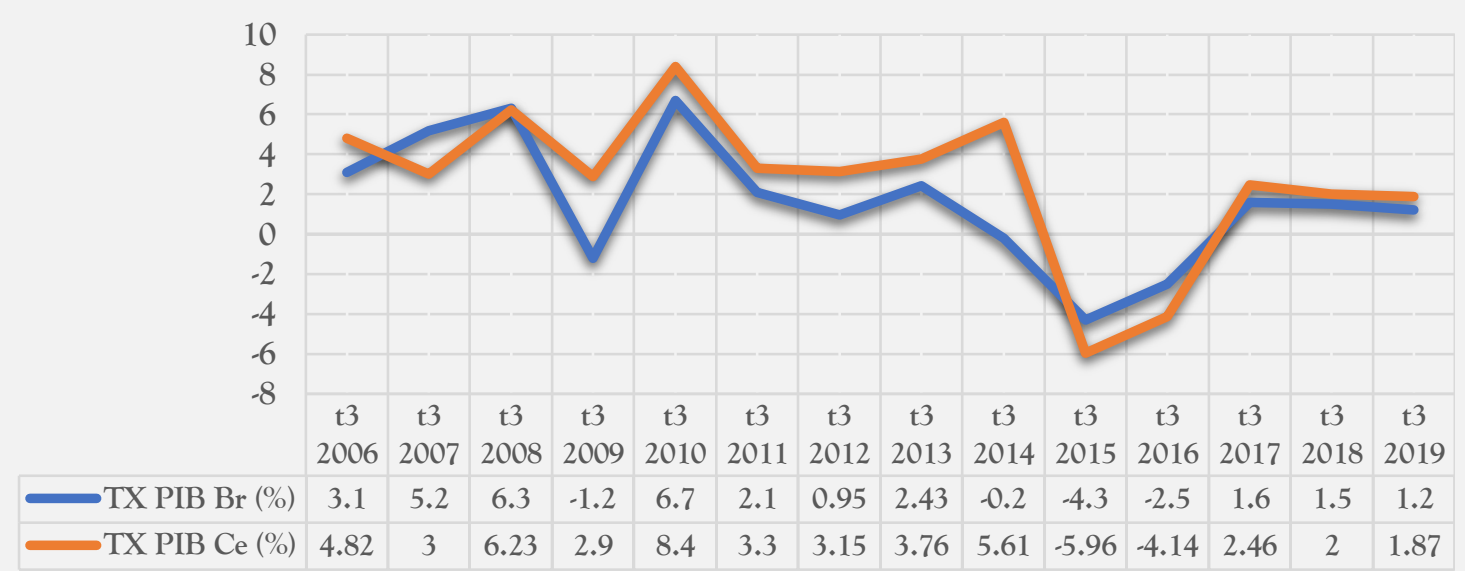

Fonte: IBGE, IPECE.

O rendimento mensal domiciliar per capita, em 2019, foi de 942 reais, ocupando o18 lugar no Brasil (IBGE, 2019). Relativamente à evolução trimestral do PIB Ceará e Brasil (\%), 2006 a 2019, ver gráfico 2.

Os dados revelam o resultado obtido pela economia estadual, em 2006, que foi influenciado pelos desempenhos dos três setores da economia cearense: o agropecuário - safras de grãos; o industrial - indústria de transformação, construção civil, extrativa mineral e eletricidade, gás e água; e o de serviços - comércio varejista.

De acordo com essas informações, o crescimento do segmento varejista do Ceará ocorreu em virtude do movimento positivo baseado na recuperação do poder de compra dos salários, na facilidade de acesso e disponibilidade de linhas de créditos (CEARÁ, 2007).

Em 2009, o Estado respondia pela $3^{\mathrm{a}}$ economia da Região Nordeste e pela $12^{\mathrm{a}}$ em relação ao Brasil, com um Produto Interno Bruto (PIB), a preços de mercado, de R \$ 60,79 bilhões e uma renda per capita de R\$ 7.385,00 (CEARÁ, 2010).

Em 2010, O PIB cearense obteve um crescimento que superou a média de aumento do PIB brasileiro. O mercado interno foi o responsável por contribuir para o crescimento econômico, incentivado pelo consumo das famílias e pelos investimentos privados. O Governo incentivou atividades importantes na geração de emprego e renda, como é o caso da construção civil, por meio da redução do IPI para os materiais de construção (CEARÁ, 2010).

Em decorrência da crise macroeconômica brasileira, em 2015, todos os Estados apresentaram queda no PIB. De acordo com o gráfico 02, observa-se uma queda acentuada, pois, no ano anterior, ocorreu a Copa do Mundo de futebol, que na época 
impulsionou o turismo, alavancando o setor de serviços e o PIB cearense (CEARÁ, 2016a).

O PIB, em 2019, manteve o ritmo de crescimento iniciado no segundo trimestre de 2017. Verifica-se que o Ceará exibe taxas de crescimento do PIB superiores às do Brasil desde o terceiro trimestre de 2018 (CEARÁ, 2020). Em todos os setores econômicos, o Ceará demonstrou crescimento.

$\mathrm{Na}$ área do turismo, o Ceará obteve o maior crescimento das atividades do setor de todo o País, segundo dados do IBGE (2020), consolidando-se como principal ponto de conexões aéreas do Nordeste e uma das principais portas de entrada de turistas estrangeiros no Brasil. Ademais, o Estado terminou 2019 com um importante saldo de empregos com carteira assinada.

No que diz respeito à segurança, os homicídios caíram pela metade, no melhor resultado da década. A taxa por 100 mil habitantes, que chegou a ser de 56,9 em 2017, caiu para 24,7 em 2019. Em Fortaleza, onde o problema da violência era ainda maior, a queda foi mais significativa, saindo de 78,1 homicídios por 100 mil habitantes, em 2013, para 24,8 (CEARÁ, 2020).

Em relação ao PIB per capita, em 2019, a projeção para o País era de R 34.429 e do Ceará de R\$ 18.878, representando 53,63\% em relação ao PIB per capita nacional (CEARÁ, 2020). Para o ano de 2020, a projeção de crescimento do PIB do Ceará é de uma taxa positiva de 2,38\%, sendo acima da taxa projetada para o Brasil - de 2,25\%.

Ao analisar os PPAs e seus eixos estratégicos dos governos de 2004/2019, percebe-se que os resultados estratégicos expressam os grandes compromissos da gestão com a sociedade e são sistematicamente monitorados com suporte em seus respectivos indicadores.

A análise da avaliação do PPA, dos programas, dos resultados estratégicos e indicadores por eixos estratégicos, visa a mensurar os avanços e os desafios que ainda persistem para o Governo, permite auxiliar a tomada de decisões estratégicas, assim como serve de instrumento de transparência - Tabela 01.

\section{- Plano Plurianual 2004/2007}

Neste período, o PPA foi reflexo da implantação do ciclo do modelo de GPR, que se resumiu em três etapas básicas: planejamento, implementação, monitoramento e 
avaliação. A etapa do planejamento definiu os resultados estratégicos, estabelecimento de metas e seus indicadores, por eixo de atuação do Plano de Governo.

A segunda fase ocorreu quando os planos estratégicos setoriais foram elaborados. Esse exercício envolveu também a racionalização de programas. Depois, ocorreu a implementação dos planos estratégicos (MEDEIROS, LISBOA, NOGUEIRA, 2009).

A terceira etapa constituiu-se em Monitoramento e Avaliação, cujo escopo foi a idealização da política pública. Em termos de monitoramento, o Governo iniciou por meio do Relatório de Performance da Setorial (RPS) e o Relatório de Performance Global (RPG). O RPS é um documento no qual cada Secretaria faz a autoavaliação dos programas e exibe o seu desempenho, servindo como prestação de contas, como responsabilização e transparência dos gastos públicos.

O PPA 2004/2007 evidenciou o eixo Ceará Vida Melhor, que se destacou e foi responsável por $58 \%$ dos recursos. Esta diretriz compreende uma série de objetivos estratégicos, que orientaram e articularam as políticas, programas, projetos e ações do Governo, dentre as quais estão: reduzir a situação de extrema pobreza; diminuir a mortalidade infantil; melhorar a esperança de vida ao nascer; reduzir o analfabetismo; melhorar a escolaridade (CEARÁ, 2007).

O eixo Ceará Empreendedor foi responsável por 27\% dos recursos, tendo o foco direcionado para a ampliação da competitividade. A consecução desse eixo está condicionada a uma ação desenvolvimentista da economia, ampliando o capital físico e aprimorando o capital humano. Nesse sentido, cinco resultados estratégicos estão sendo trabalhados: crescimento econômico diversificado; a inserção internacional; geração de emprego de qualidade; equilíbrio fiscal; e infraestrutura competitiva (CEARÁ, 2007).

Assim, neste período, este eixo possibilitou o crescimento econômico diversificado, o crescimento do PIB; da renda per capita; no fluxo do comércio internacional; em 37 mil novos postos de trabalho; e diminuição da dívida pública em relação ao PIB.

Em relação ao eixo de CE Integração, o governo não conseguiu atingir os resultados estratégicos planejados, porquanto não melhorada a distribuição territorial da renda e do emprego e a inclusão social territorialmente equilibrada, pois se concentraram a renda e as ocupações na Região Metropolitana de Fortaleza.

Revista Brasileira de Políticas Públicas e Internacionais, v. 5, n. 1, abr./2020, pp. 105-128. 
$\mathrm{O}$ eixo CE serviço do cidadão voltou-se às atividades governamentais que possibilitaram e melhoraram a transparência da Gestão Pública por meio da criação de canais de interação com o cidadão, por intermédio de dois equipamentos - a Ouvidoria do Estado e o Portal do Governo.

Ademais, foi melhorada a eficiência no uso do recurso público, por meio do Resultado Primário. Por esse pretexto, o Governo trabalhou com uma gestão físcal criteriosa, resultando num Superávit Primário, garantindo a amortização da dívida pública (CEARÁ, 2007).

\section{- Planos Plurianuais 2008/2011 e 2012/2015}

No eixo governo participativo, ético e competente, foram propostas políticas setoriais e temáticas de promoção da intersetorialidade, redução das desigualdades sociais e regionais, o que exigiu a adoção de instrumentos e práticas modernas de planejamento e gestão fiscal, visando a democratizar a formulação e o acompanhamento das políticas públicas, conferir transparência às informações e realizar, com a devida competência, o serviço prestado à população.

Com esse propósito, os resultados são: Participação cidadã na formulação e controle das políticas públicas; Gestão qualificada e ágil; Aumento da capacidade de investimento; e Eficiência nos gastos públicos.

Observa-se que este eixo foi o maior direcionador de alocação de recursos, sendo $42 \%$ (2008/2011) e 41\% (2012/2015). Destacam-se o aperfeiçoamento dos processos de relacionamento com os meios de comunicação, o diálogo com representações da sociedade e as relações com os poderes constituídos, por meio do PPA, elaborado de maneira participativa em oficinas nas oito macrorregiões do Ceará (CEARÁ, 2016b).

Tabela 01: Evolução dos Eixos Estratégicos por Meio dos PPAs 2004/2019

\begin{tabular}{|c|c|c|c|c|c|}
\hline \multicolumn{2}{|c|}{ Eixos Estratégicos } & 2.004 & 2005-2007 & Total & $\%$ \\
\hline \multirow{4}{*}{$\begin{array}{c}\text { PPA } \\
\text { 2004/2007 }\end{array}$} & CE Empreendedor & 1.543.707.221,11 & $5.392 .595 .876,21$ & $6.936 .303 .097,32$ & $27 \%$ \\
\hline & CE Vida Melhor & $3.640 .023 .889,00$ & $11.079 .838 .206,00$ & $14.719 .862 .095,00$ & $58 \%$ \\
\hline & CE Integração & $105.062 .970,00$ & $277.586 .908,00$ & $382.649 .878,00$ & $2 \%$ \\
\hline & CE à serviço do idadão & $760.500 .663,00$ & $2.473 .445 .813,00$ & $3.233 .946 .476,00$ & $13 \%$ \\
\hline \multicolumn{2}{|l|}{ Total } & 6.049.294.743,11 & 19.223.466.803,21 & 25.272.761.546,32 & $100 \%$ \\
\hline \multicolumn{2}{|c|}{ Eixos Estratégicos } & 2.008 & $2009-2011$ & Total & $\%$ \\
\hline \multirow{3}{*}{$\begin{array}{c}\text { PPA } \\
2008 / 2011\end{array}$} & $\begin{array}{l}\text { Sociedade Justa e } \\
\text { Solidária } \\
\end{array}$ & $3.903 .277 .126,00$ & $12.458 .678 .986,00$ & $16.361 .956 .112,00$ & $35 \%$ \\
\hline & $\begin{array}{l}\text { Economia p/ uma vida } \\
\text { melhor }\end{array}$ & $3.156 .899 .662,00$ & 7.202.378.300,00 & 10.359.277.962,00 & $22 \%$ \\
\hline & $\begin{array}{l}\text { Governo Participativo, } \\
\text { Ético e competente }\end{array}$ & 4.392.933.115,00 & 15.298.919.779,00 & $19.691 .852 .894,00$ & $42 \%$ \\
\hline
\end{tabular}

Revista Brasileira de Políticas Públicas e Internacionais, v. 5, n. 1, abr./2020, pp. 105-128. 
Castelo. A Gestão Pública e o Desempenho

\begin{tabular}{|c|c|c|c|c|c|}
\hline \multicolumn{2}{|l|}{ Total } & 11.453.109.903,00 & 34.959.977.065,00 & 46.413.086.968,00 & $100 \%$ \\
\hline \multicolumn{2}{|c|}{ Eixos Estratégicos } & 2.012 & 2013-2015 & Total & $\%$ \\
\hline \multirow{3}{*}{$\begin{array}{c}\text { PPA } \\
2012 / 2015\end{array}$} & $\begin{array}{l}\text { Sociedade Justa e } \\
\text { Solidária }\end{array}$ & 7.395.485.300,40 & $21.090 .867 .960,07$ & $28.486 .353 .260,47$ & $34 \%$ \\
\hline & $\begin{array}{l}\text { Economia p/ uma vida } \\
\text { melhor }\end{array}$ & 4.172.782.210,41 & $16.462 .665 .353,30$ & $20.635 .447 .563,71$ & $25 \%$ \\
\hline & $\begin{array}{l}\text { Governo Participativo, } \\
\text { Ético e competente } \\
\end{array}$ & $6.771 .555 .476,32$ & 27.014.720.161,12 & $33.786 .275 .637,44$ & $41 \%$ \\
\hline \multicolumn{2}{|l|}{ Total } & $18.339 .822 .987,13$ & $64.568 .253 .474,49$ & $82.908 .076 .461,62$ & $100 \%$ \\
\hline \multicolumn{2}{|c|}{ Eixos Estratégicos } & 2.016 & 2017-2019 & Total & $\%$ \\
\hline \multirow{7}{*}{$\begin{array}{c}\text { PPA } \\
2016 / 2019\end{array}$} & $\begin{array}{l}\text { CE Gestão Dem.por } \\
\text { Resultados }\end{array}$ & $16.277 .311 .498,00$ & $55.116 .385 .810,00$ & 71.393.697.308,00 & $68 \%$ \\
\hline & CE Acolhedor & $405.639 .666,00$ & $1.352 .301 .497,00$ & $1.757 .941 .163,00$ & $2 \%$ \\
\hline & CE de Oportunidades & $2.848 .592 .768,00$ & $6.739 .731 .115,00$ & $9.588 .323 .883,00$ & $9 \%$ \\
\hline & CE Sustentável & $1.023 .896 .938,00$ & $1.936 .183 .404,00$ & $2.960 .080 .342,00$ & $3 \%$ \\
\hline & CE do Conhecimento & $1.468 .202 .950,00$ & $3.851 .903 .268,00$ & $5.320 .106 .218,00$ & $5 \%$ \\
\hline & CE Saudável & $2.782 .770 .912,00$ & $9.438 .197 .668,00$ & $12.220 .968 .580,00$ & $12 \%$ \\
\hline & CE Pacífico & $451.025 .517,00$ & $1.551 .909 .036,00$ & $2.002 .934 .553,00$ & $2 \%$ \\
\hline \multicolumn{2}{|l|}{ Total } & $25.257 .440 .249,00$ & 79.986.611.798,00 & $105.244 .052 .047,00$ & $100 \%$ \\
\hline
\end{tabular}

Fonte: Elaboração própria.

Assim também ocorreu com o aumento da capacidade de investimentos do

Estado, que se confirmou, em decorrência de uma política fiscal responsável. O esforço do Governo para aumentar a arrecadação própria mediante ações para obtenção da eficiência tributária e do combate à sonegação atrelada à implementação de uma política de controle gerencial dos gastos correntes, do fortalecimento da poupança pública e do baixo nível de endividamento, permitiu que o Governo se capacitasse para manter seu programa de investimentos públicos (CEARÁ, 2016b).

No eixo Sociedade Justa e Solidária, estão consolidados resultados estratégicos para o alcance de novos patamares na prestação do atendimento dos setores sociais, para melhoria das condições de vida, trabalho e garantia de direitos à população.

Para avaliar as melhorias efetivas das políticas integrantes desse Eixo, foram definidos cinco resultados estratégicos: Educação Básica Ampliada e com Qualidade; Educação Superior e Profissionalizante com Ênfase nas Potencialidades do Estado; População com Acesso à Saúde Descentralizada e com Qualidade; População mais Segura e com Garantia de Direitos; e Juventude com Oportunidades de Inserção Produtiva e Social.

Este eixo no PPA representou 35\% (2008/2011) e 34\% (2012/2015) dos recursos públicos. Destaca-se a função Educação como base do projeto de desenvolvimento do Estado, cuja política tem como objetivo assegurar oportunidades mais igualitárias na promoção do desenvolvimento pessoal, social e econômico.

Revista Brasileira de Políticas Públicas e Internacionais, v. 5, n. 1, abr./2020, pp. 105-128. 
Assim, a implementação destas diretrizes permitiu a evolução dos Índices de Desenvolvimento da Educação Básica - IDEB do Estado nas séries iniciais e finais do Ensino Fundamental; do Índice de Desenvolvimento da Educação Básica - IDEB da Rede Estadual do Ensino Médio; a diminuição da Taxa de analfabetismo das pessoas de 15 anos e mais de idade; o aumento da Taxa de Escolarização Líquida do Ensino Médio; e Escolaridade Média das Pessoas de 15 anos e mais de idade.

No eixo economia para uma vida melhor, o objetivo foi promover o crescimento econômico com reflexos em indicadores sociais, aliado à proteção ambiental e à modernização da infraestrutura para o desenvolvimento. Assim, orienta a ação de Governo na direção de cinco resultados estratégicos: Crescimento Econômico com Competitividade; Aumento da Sustentabilidade Ambiental; Redução das Desigualdades Inter-regionais; Sociedade com Renda maior e mais bem Distribuída; e Infraestrutura Estratégica Ampliada.

Para assegurar as bases requeridas, o governo definiu como resultado a "Ampliação da infraestrutura estratégica" apoiada na melhoria da logística do setor de transportes e no aumento da capacidade de acumulação hídrica, tais como: ampliação do porto do Pecém, implantação da Refinaria e Siderúrgica e a Zona de Processamento de Exportação - ZPE, bem assim o fortalecimento da infraestrutura hídrica (CEARÁ, 2016b).

\section{- Plano Plurianual 2016/2019}

O eixo Ceará da Gestão Democrática por Resultados é a organização das ações governamentais, de maneira planejada para uma execução eficaz e eficiente, de modo a contribuir para o desenvolvimento de políticas públicas integradas e cuja atenção está concretamente direcionada às necessidades dos cidadãos. Neste sentido, busca-se assegurar no Estado o crescimento econômico constante, o equilíbrio financeiro fiscal e orçamentário e a redução de desigualdades imanentes às realidades sociais vigentes (CEARÁ, 2020).

Este eixo é o principal e é responsável por $68 \%$ dos recursos, tendo como ponto de partida o alcance de resultados por meio do planejamento estratégico, democrático, inclusivo e participativo. Além disso, visa à pactuação de resultados exequíveis, mensuráveis e transparentes, dotados de eficiência, eficácia e efetividade por meio dos acordos estratégicos (CEARÁ, 2020).

Revista Brasileira de Políticas Públicas e Internacionais, v. 5, n. 1, abr./2020, pp. 105-128. 
Este modelo adota a contratualização de resultados, instigando a mudança de atitude dos gestores públicos e a conscientização acerca dos compromissos pactuados. Isto condiciona o ciclo de formulação do planejamento, orçamento e gestão. Por conseguinte, foram obtidos a integração de eixos estratégicos, o enlace de processos, recursos, programas e produtos com os resultados, assim como a internalização e o compartilhamento de mecanismos de monitoramento intensivo e avaliação perene (CEARÁ, 2020).

\section{Considerações Finais}

Sobrou evidenciada neste ensaio a evolução da Gestão Pública por meio de suas abordagens, caracterizando seus mais relevantes ideais e alteados conceitos. Logo depois, mostrou-se a repercussão destes movimentos no contexto brasileiro. Por fim, configurouse a gestão por meio de resultados do Governo do Ceará que caracterizou a política de GMD.

Certificou-se, portanto, o objetivo do estudo, de evidenciar o desempenho governamental sob o contexto da Gestão Pública brasileira, bem como restaram descritos e analisados, por meio do estudo de caso, a GpR do Estado e o positivo cumprimento de suas políticas públicas.

O esforço do Estado brasileiro na promoção do desempenho caracterizou-se pela implantação e consolidação de modelos materializados pelas reformas administrativas, que demandaram tempo e esforço concentrado, um patrocínio superior, disciplina e continuidade, com intuito de execução e enraizamento de uma cultura de resultado nas instituições dos Estados.

Destaca-se, também, a política de GpR do Ceará, demonstrada por meio de uma política fiscal austera e efetiva, que serviu como referência para as outras unidades federativas, porquanto evidenciou o fortalecimento da cultura de GpR; pelo alinhamento entre os instrumentos de planejamento; pelo empoderamento dos gestores e políticos na elaboração e implementação de políticas públicas; e pela transparência nas prioridades do Governo.

A institucionalização desse modelo significa mudar o comportamento dos servidores, políticos e parceiros para uma visão de resultados de longo prazo e de um valor pendido para o bem-estar comum.

Revista Brasileira de Políticas Públicas e Internacionais, v. 5, n. 1, abr./2020, pp. 105-128. 
Malgrado, entretanto, os avanços evidenciados pelo Estado, os resultados sociais e ambientais não avançaram do mesmo modo. Assim, continua ainda severa a existência da concentração de riqueza, da ampla e evidente pobreza da região e da violência urbana do Estado. Não obstante os investimentos ambientais e exercícios institucionais na condução de uma política ambiental, os problemas urbanos ainda evidenciam a má gestão da coleta de lixo e resíduos sólidos e uma defeituosa mobilidade urbana, o que se terá de consertar em futuro não muito remoto.

Ademais, este trabalho sistematiza conhecimentos práticos e teóricos relacionados à área da Gestão Pública e desempenho no Brasil e no Ceará, evidenciando seu percurso e identificando os principais fatos que caracterizaram esta senda de conhecimento, servindo de subsídio para futuros ensaios teóricos e tarefas práticas atinentes à matéria.

Pesquisas empíricas adicionais são necessárias e indispensáveis, a fim de enriquecer a compreensão sobre as especificidades da GpR. Preencheu-se, também importa exprimir por oportuno - a lacuna da literatura que aborda sobre a GMD.

Como limitação desta demanda, tem-se a perspectiva do estudo sobre o desempenho público ser em relação a uma região do Estado Brasileiro, o que reduz a generalização dos resultados.

As evidências práticas do estudo exprimem que o Governo deve ter cuidado em desenvolver uma cultura por via de resultado, em razão de seus reflexos interferirem no serviço ofertado e no desempenho público. Quanto às implicações acadêmicas, a implementação da GpR por meio de práticas de GMD servem como expedientes que avaliam e mensuram o desempenho do Governo.

\section{Referencias}

Bao, G. et al. (2013) 'Beyond New Public Governance: A Value-Based Global Framework for Performance Management, Governance, and Leadership', Administration \& Society, 45(4), pp. 443-467.

Barabashev, A. G. and Klimenko, A. V (2017) 'Russian Governance Changes and Performance', Chinese Political Science Review. Springer Singapore, 2(1, SI), pp. $22-$ 39. Bouckaert, G. and Halligan, J. (2008) Managing Performance: international comparisons. Edited by T. \& Francis. New York.

Bresser-pereira, L. C. (1999) 'Reforma gerencial do Estado, teoria política e ensino da administração pública Reforma gerencial do Estado , teoria política e ensino da administração pública', (1987), pp. 1-6.

Revista Brasileira de Políticas Públicas e Internacionais, v. 5, n. 1, abr./2020, pp. 105-128. 
Brusca, I., Manes Rossi, F. and Aversano, N. (2017) 'Performance Measurement in Italian and Spanish Local Governments: Comparative Policy Analysis', Journal of Comparative Policy Analysis: Research and Practice. Routledge, 19(5), pp. 470-486.

Capobiango, R. P. N., Silva, A. de L. and Faroni, E. A. W. (2013) 'REFORMAS ADMINISTRATIVAS NO BRASIL: UMA ABORDAGEM TEÓRICA E CRÍTICA', REGE - Revista de Gestão, v. 20(1), pp. 61-78.

Carter, Bob, et al. (2013) 'Taxing times: lean working and the creation of (in) efficiencies in HM Revenue and Customs.', Public Administration, 91(1), pp. 83-97.

Cavalcante, P. L. (2019) 'Trends in Public Administration after Hegemony of the New Public Management : a literature review', Revista do, 70(2), pp. 195-218.

CEARA (2007) Mensagem à Assembléia Legislativa - 2007. Fortaleza.

CEARA (2010) Mensagem à Assembleia Legislativa - 2010. Fortaleza- Ceará.

CEARA (2016a) 'Mensagem à Assembléia Legislativa - 2016.', pp. 1-220.

CEARA (2016b) Plano plurianual 2012 - 2015: relatório de avaliação. Fortaleza- Ceará.

CEARA (2019a) Gestão para Resultados: pactuação de compromissos. Fortaleza- Ceará.

CEARA (2019b) Introdução à gestão para resultados. Fortaleza- Ceará.

CEARA (2020) Mensagem à Assembleia Legislativa - 2020. Fortaleza- Ceará.

Dal Molin, M., Turri, M. and Agasisti, T. (2017) 'New Public Management Reforms in the Italian Universities: Managerial Tools, Accountability Mechanisms or Simply Compliance?', International Journal of Public Administration. Routledge, 40(3), pp. 256-269.

de Freitas, C. A. S. (1999) 'A implementação do Government Performance and Results Act na administração pública dos EUA’, Revista do Serviço Público, 50(3), pp. 92-121.

Eliuz, S. et al. (2017) 'Predictors of an Effective Performance Measurement System: Evidence from Municipal Governments in Turkey', International Journal of Public Administration. Routledge, 40(4), pp. 329-341.

Ensslin, L. et al. (2017) 'Avaliação multicritério de desempenho: o caso de um Tribunal de Justiça', Cadernos Gestão Pública e Cidadania, 22(71), pp. 57-82.

Faria, J. R. V. and Faria, J. H. (2017) 'A Concepção de Estado e a Administração Pública no Brasil no Âmbito do Plano Diretor de Reforma do Estado', Administração Pública \& Gestão Social, 9(3), pp. 140-147.

Revista Brasileira de Políticas Públicas e Internacionais, v. 5, n. 1, abr./2020, pp. 105-128. 
Gomes, P., Mendes, S. M. and Carvalho, J. (2017) 'Impact of PMS on organizational performance and moderating effects of context', International Journal of Productivity and Performance Management, 66(4), pp. 517-538.

Han, C. and Kim, S. (2017) 'The Changing Modes of Administrative Reform in South Korea', Transylvanian Review of Administrative Sciences, 2017(50E), pp. 54-72.

Jurnali, T. (2015) 'Performance Management System for Local Government: The Indonesian Experience’, Global Business Review, 16(3), pp. 351-363.

Maciel, Everton Cabral et al. (2019) 'Acordo de Resultados: processo decisório baseado em evidências do Governo do Ceará', in III Congresso Internacional de Desempenho do Setor Público, pp. 1973-1987.

Maciel, Everton Cabral; et al. (2019) 'A Cultura de Resultados e os Resultados da Cultura.', in III Congresso Internacional de Desempenho do Setor Público, pp. 198-213.

Medeiros, A. C. C., Lisboa, A. and Nogueira, C. A. G. (2009) Gestão Pública por Resultados: A experiência do Estado do Ceará Comparada ao modelo Canadense.

Monteduro, F. (2017) 'The Adoption of Outcome-Related Performance Indicators in External Reporting: An Empirical Study', International Journal of Public Administration. Routledge, 40(10), pp. 860-874.

Mota, P. R. de M. (2013) 'O estado da arte da gestão pública', Revista de Administração de Empresas, 53(jan/fev), pp. 82-90.

Paes de Paula, A. P. (2005) 'Administração pública brasileira entre o gerencialismo e a gestão social', Revista de Administração de Empresas, pp. 1-23.

Piovan, T. T. de C. et al. (2019) 'Orçamento para resultados: a experiência do estado do Ceará', in III Congresso Internacional de Desempenho do Setor Público, pp. 2044-2058.

Pollitt, C. and Bouckaert, G. (2004) Public Management Reform: A Comparative Analysis. (2nd ed. Edited by O. Oxford University Press. Oxford.

Tabi, M. T. and Verdon, D. (2014) 'New public service performance management tools and public water governance: The main lessons drawn from action research conducted in an urban environment 1', International Review of Administrative Sciences, 80(1), pp. 213 235 .

Verbeeten, F. H. M. and Speklé, R. F. (2015) 'Management Control, Results-Oriented Culture and Public Sector Performance: Empirical Evidence on New Public Management', Organization Studies, 36(7), pp. 953-978.

Virtanen, P. and Vakkuri, J. (2015) 'Searching for Organizational Intelligence in the Evolution of Public-Sector Performance Management', Journal of Public Administration and Policy, 8(2), pp. 89-99. 